\title{
Двухлучевой интерферометр на основе кварцевого светоделительного блока с неподвижным фотоприемником и имитацией вращательной перестройки
}

\author{
С.Л. Микерин, В.Д. Угожаев ${ }^{*}$ \\ Институт автоматики и электрометрии СО РАН \\ *E-mail: vdu@iae.nsk.su
}

DOI: 10.31868/RFL2020.207-208

Двухлучевые интерферометры с возможностью варьирования периода записываемых дифракционных решеток широко востребованы в различных областях голографии и фотоники, например, для исследования свойств фотополимерных материалов и записываемых в них голограмм [1], для записи в оптических волокнах массивов распределенных брэгговских решеток (ВБР) в качестве датчиков физического состояния волокна [2] и для других применений. В [3] описан интерферометр на основе светоделительного кубика (СДК) с двумя зеркалами и фотоприемником (ФП), неподвижными относительно СДК, в котором стабилизация положения интерференционной картины (ИК) при варьировании угла схождения парциальных световых пучков (ПП) обеспечивается взаимно согласованными линейным и угловым перемещениями подвижного зеркала (ПЗ), направляющего световой пучок в СДК.Такие интерферометры удается объединять в системы для записи двумерных решеток с независимой установкой периода в каждом измерении [4]. Однако для записи протяжённых ВРБ (10-15 мм) более подходящим представляется интерферометр на основе светоделительного блока (СДБ) [5], поскольку в нем длина хода световых пучков в материале СДБ более чем в 3 раза короче по сравнению с СДК соответствующих габаритов. Целью данного доклада является анализ перестройки периода в интерферометре на основе СДБ из кварцевого стекла при стабилизации положения ИК, обеспечиваемой согласованием линейного и углового перемещений ИП на входе в СДБ посредством механизма имитации вращения [3].

На рис. 1 представлена оптическая схема исследованного интерферометра, ход световых пучков отображается их осями. Интерферометр, включающий в себя СДБ 1 и два зеркала 3.1 и 3.2, оптически связан с ФП 4, который удален от торца $\mathrm{C}_{2} \mathrm{C}_{3}$ на расстояние $L_{\mathrm{ph}}$. СДБ представляет собой две плотно состыкованные рабочими поверхностями идентичные пластины из кварцевого стекла длиной $M$ и толщиной $A \approx 0,15 M$ с делительным зеркалом (ДЗ) 2 между ними. Зеркала установлены симметрич-

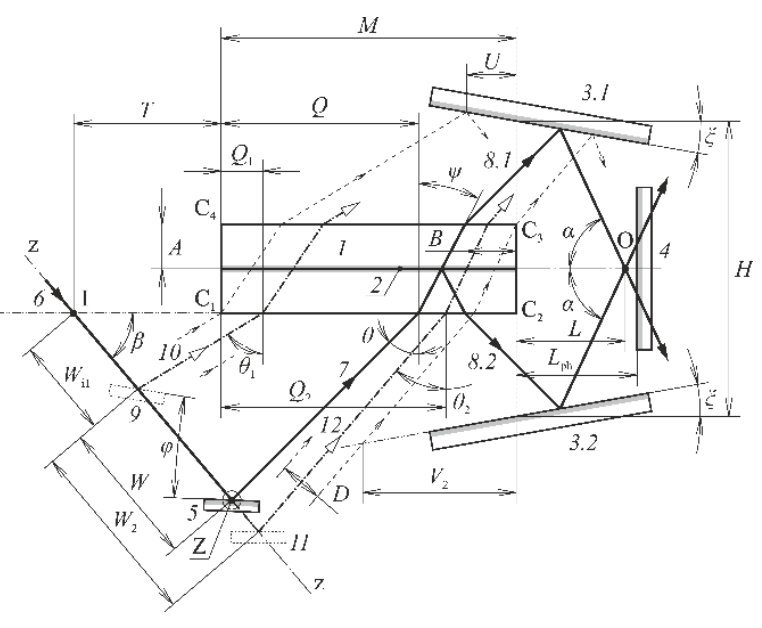

Рис. 1. Оптическая схема интерферометра но к плоскости ДЗ на расстоянии $H$ друг от друга под углом $\xi$ (на рис. $1 \xi>0$ ). Исходный световой пучок (ИП) 7 диаметром $D$ направляется на входную поверхность $\mathrm{C}_{1} \mathrm{C}_{2}$ на расстоянии $Q$ от края $\mathrm{C}_{1}$ под углом падения $\theta$ посредством ПЗ 5 и 
далее расщепляется ДЗ на два ПП 8.1 и 8.2. После отражения от зеркал оси этих пучков пересекаются в точке О под углом схождения $2 \alpha$ на расстоянии $L \approx L_{\mathrm{ph}}$ от торца $\mathrm{C}_{2} \mathrm{C}_{3}: \alpha=90^{\circ}+2 \xi-\theta$.

Текущее положение ПЗ задается координатами $W$ и $\varphi$. Перемещение ПЗ выполняется вдоль входного пучка 6 от начального положения $9\left(W_{1}=0, \varphi_{1}=0\right)$ до конечного положения $11\left(W_{2}, \varphi_{2}\right)$, соответствующие нижнему $10\left(Q_{1}, \theta_{1}\right)$ и верхнему $12\left(Q_{2}, \theta_{2}\right)$ граничным положениям ИП. Последние обусловлены касанием ИП края $\mathrm{C}_{1}$ и касанием ПП краев $\mathrm{C}_{2}, \mathrm{C}_{3}$. В свою очередь па́ры координат ИП $\left(Q_{1}, \theta_{1}\right)$ и $\left(Q_{2}, \theta_{2}\right)$ удовлетворяют условию $L \approx L_{\text {fix }}=$ const, поддерживаемому во всем промежутке между ними. Такое движение ИП определяется формулой:

$$
Q=M-2 A \operatorname{tg} \psi-\left[H \sin (\theta-\xi) \cos \xi-A \sin \theta-L_{\mathrm{fix}} \cos (\theta-2 \xi)\right] / \cos \theta,
$$

где $\operatorname{tg} \psi=\sin \theta / \sqrt{n^{2}-\sin ^{2} \theta}, n-$ показатель преломления материала СДБ. Граничные положения находятся численно по упомянутым выше условиям касания: $Q_{1}=\mathrm{D} /\left(\cos \theta_{1}\right), Q_{2}=M-2 A \operatorname{tg} \psi_{2}-D /\left(\cos \theta_{2}\right)$ и задают соответствующие граничные значения угла $\alpha: \alpha_{1}$ и $\alpha_{2}$, а также ширину диапазона перестройки этого угла: $\Delta \alpha=\alpha_{2}-\alpha_{1}$. Зависимость $Q(\theta)$, полученная из (1), близка к линейной для широкого набора сочетаний параметров $H$ и $L_{\text {fix }}$, что открывает возможность использовать в качестве механизма согласования линейного и углового перемещений ПЗ рычажный механизм в [3]. Анализ зависимости $Q(\theta)$ производился с учетом виньетирования рабочими поверхностями СДБ (параметр $G$ ) и/или зеркалом со стороны входной поверхности (параметры $U, V$ и $V_{2}$ ). Параметры $G$ и $V$ для текущего положения ИП определяются аналогично параметрам $U$ и $V_{2}$ (см. рис. 1). Это ограничение возможно в случае $H \approx M$ и $L_{\mathrm{fix}}<M$ при $\xi<0$.

На рис. 2 показано разграничение массива параметров $h=H / M$ и $l_{\text {fix }}=L_{\mathrm{fix}} / M$ по критерию наличия или отсутствия виньетирования в исследуемом интерферометре при $\xi=-15^{\circ}$. Выше кривой 1 располагается зона массива, свободная от виньетирования; ниже кривой 2 световые пучки перекрываются частично или полностью во всем диапазоне перестройки, ограничиваемом условиями касания. Между кривыми 1 и 2 - диапазоны перестройки частично ограничены виньетированием. Кривые 3 и 4 являются экстраполяцией соответствую-

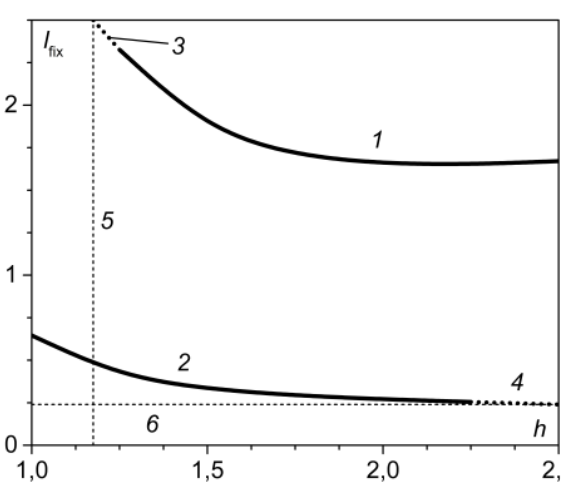

Рис. 2. Зоны виньетирования щих кривых 1 и 2 на края исследованного массива; $5-h=1,175 ; 6-l_{\mathrm{fix}}=0,24$. Например, для записи ВБР с $\lambda_{\mathrm{5}}=1 . .2$ мкм в кварцевом волокне с $n=1,5$ возможна практическая реализация интерферометра, характеризуемого па́рами параметров $\left(h ; l_{\mathrm{fix}}\right):(1,0 ; 1,25),(1,0 ; 1,75),(1,25 ; 2,5)$. Механизм имитации вращения анализируется аналогично [3].

\section{Литература}

[1] В.В. Шелковников, Е.В. Васильев и др., Оптика и спектроскопия 99, 806-815 (2005)

[2] J. Habel, T. Boilard, Y. Messadeq, F. Trépanier, M. Bernier, Advanced Photonics Congress (BGPP, IPR, NP, Networks, NOMA, Sensors, SOF, SPPCom) OSA, BM3A.4 (2010)

[3] С.Л. Микерин, В.Д. Угожаев, Прикладная фотоника 5, № 3, 218-237 (2018)

[4] С.Л. Микерин, В.Д. Угожаев, Междунар. науч. конференция «СибОптика-2018»: Сб. Трудов в 2-х т. - Н-сиб.: СГУГиТ, Т. 1, 101-107 (2018)

[5] В.Д. Угожаев, Автометрия 54, № 4, 67-77 (2018) 